\title{
ARTÍCULOS
}

\section{LAS HOGUERAS DE LA NOCHE DE SANT JOAN Y LA DESACTIVACIÓN DE LA CULTURA INFANTIL DE CALLE EN BARCELONA}

\author{
SANT JOAN BONFIRES AND THE DEACTIVATION OF CHILDREN STREET \\ CULTURE IN BARCELONA
}

\author{
Manuel Delgado Ruíz ${ }^{1}$ \\ Universidad de Barcelona
}

\section{Marta Contijoch Torres²}

Universidad de Barcelona

\section{Helena Fabré Nadal ${ }^{3}$}

Instituto de Investigaciones Dr. José María Luis Mora

Recibido: 26 de noviembre de 2019; Aprobado: 11 de febrero de 2021.

\begin{abstract}
Cómo citar este artículo / Citation: Delgado Ruíz, Manuel, Marta Contijoch Torres y Helena Fabré Nadal. 2021. "Las hogueras de la noche de Sant Joan y la desactivación de la cultura infantil de calle en Barcelona". Disparidades. Revista de Antropología 76(2): e016. doi: <https://doi.org/10.3989/dra.2021.016>.
\end{abstract}

RESUMEN: A mediados de la década de los 60 del siglo pasado, cada noche del 23 de junio se encendían sin permiso cientos de hogueras en todos los barrios de Barcelona. Esos fuegos eran el resultado de la actividad de una chiquillería autoorganizada que se encargaba de recoger la madera días antes, custodiarla y montar con ella las piras. En la actualidad apenas quedan menos de dos decenas de fuegos de Sant Joan en la capital catalana, todos preparados por adultos y con la debida autorización. Los factores que han motivado la práctica desaparición de una costumbre con más de dos siglos de historia y que había llegado a ser masiva, han sido varios. A partir de una investigación sobre la memoria de quienes fueron preadolescentes hace décadas, se pone el acento en una de esas razones: la que pone en relación el declive de la cultura popular infantil de calle con la implantación con éxito de una importante oferta de educación en el tiempo libre, que fue suprimiendo la presencia de pandillas de niños y niñas en las calles, concebidas cada vez más como lugares de riesgo y depravación.

PALABRAS CLAVE: Infancia; Calle; Juego; Pedagogía del tiempo libre; Cultura popular; Barcelona.

1 Correo electrónico: manueldelgado@ub.edu. ORCID iD: <https://orcid.org/0000-0002-1208-8850>.

2 Correo electrónico: martacontijoch@ub.edu. ORCID iD: <https://orcid.org/0000-0002-8424-0954>.

3 Correo electrónico: helenafabrenadal@gmail.com. ORCID iD: <https://orcid.org/0000-0002-1284-7511>. 
ABSTRACT: During the 60 s, every June $23^{\text {rd }}$, without permission, hundreds of bonfires were burnt during the night in all the neighbourhoods of Barcelona. These were a result of children's auto-organised activity, in charge of piking the wood up several days before, guarding it and staging the bonfires. Nowadays, less than twenty of those bonfires burn in the Catalan capital. Adults, with authorisation of the city council, prepare them all. Several factors have caused the virtual extinction of a tradition that traces back two centuries, with a grand following in the last one. Based on research about the memory of those who were preadolescents some decades ago, this paper focuses on one of the reasons why this tradition hasn't survived: the decline of children in the street as popular culture connected with the introduction of leisure education, ending the presence of children on the streets; streets which are now seen as places of danger and depravation.

KEYWORDS: Childhood; Street; Play; Leisure Pedagogy; Popular Culture; Barcelona.

Copyright: @ 2021 CSIC. Este es un artículo de acceso abierto distribuido bajo los términos de la licencia de uso y distribución Creative Commons Reconocimiento 4.0 Internacional (CC BY 4.0).

\section{INTRODUCCIÓN}

«Me asomé a la ventana de Angustias, en camisón. Vi el cielo enrojecido en varios puntos por el resplandor de las Ilamas. La misma calle de Aribau ardió en gritos durante mucho tiempo, después se encendieron dos o tres hogueras en distintos cruces con otras calles. Un rato después, los muchachos saltaron sobre las brasas». (Laforet 2012 [1944]: 228-229)

En uno de los momentos de su novela Nada, aparecida en 1944, Carmen Laforet hace que su protagonista, Andrea, se asome al balcón de una calle céntrica del Eixample barcelonés, a la hora en que empezaba a oscurecer la vigilia del 24 de junio, festividad de San Juan Bautista. El espectáculo al que asiste es el de cómo, en varias confluencias accesibles a la vista, empezaban a arder fogatas que acababa de prender la chiquillada. Esa imagen, común a todas las ciudades y pueblos catalanes, podía contemplarse en todos los barrios de Barcelona, fuera cual fuera su morfología y su composición social, la noche del 23 de junio. Es difícil encontrar un cronista de lo que era la vida en la capital catalana hasta casi finales del siglo pasado que no aluda al espectáculo de bandadas de preadolescentes trajinando muebles viejos para amontonarlos en una pira a la que luego prendían fuego. Difícil que un poeta o novelista que haya escogido Barcelona como tema o escenario haya eludido la oportunidad dramática que le brinda la noche de Sant Joan 4 . Canciones, obras teatrales y películas completarían la prueba de la incidencia en el imaginario creativo

4 Vamos a emplear Sant Joan en lugar de San Juan para referirnos a la fiesta del solsticio de verano en Cataluña como forma de subrayar su especificidad. De hecho, la prensa catalana en castellano así lo hace. Por ejemplo, <https://www.elperiodico.com/es/sociedad/20190623/ sant-joan-la-noche-mas-corta-del-ano-se-ilumina-conhogueras-7519142>, consultado 25/11/2019. asociado a Barcelona una noche de verano como esa, sin duda, todavía hoy, aunque sin apenas hogueras, la fiesta más masiva de las que se celebran en la ciudad y la única que la abarca en su totalidad.

Costaría dar con algún barcelonés de más de 45 años que no reconociera haber participado, cuando fue niño, de la preparación y encendido de las hogueras de Sant Joan. Así lo acredita el trabajo de investigación llevado a cabo entre mediados de 2015 y durante todo $2016^{5}$, que obtuvo informaciones de 213 vecinos y vecinas de diferentes barrios de Barcelona, de entre esa edad y hasta los 70 años, a propósito de cómo se desarrollaba la recolección y custodia de madera y la preparación y encendido de las hogueras a cargo de ellos mismos, cuando tenían entre 8 y 14 años. En algunos casos, el testimonio se obtuvo en conversaciones informales e hizo posible todo un mapeo de cómo esta actividad dejaba huella en la trama urbana y lo hacía promoviendo una especie de cartografía simbólica de la que los puntos fuertes eran los que marcaban las respectivas hogueras, a la manera de monumentos efímeros, que, tras un complicado sistema ritual que se prolongaba a lo largo de varios días, concluía con su destrucción pública. En

5 La investigación respondió a un encargo del Servei de Cultura Popular de l'Ajuntament de Barcelona y contó, además, con ayudas del Institut Ramon Muntaner, IRMU (ref. Ap36/16) y del Observtori del Patrimoni Etnogràfic Immaterial, OPEI, del Departament de Cultura de la Generalitat (ref. 16S00440-0), que recibieron el Institut Català d'Antropologia y el Observatori d'Antropologia del Conflicte Urbà, OACU. Conformaron el equipo de trabajo Maria Amer, Júlia Corsunsky, Enric Rubiella, Oriol Palmero, Marcel Pich, Mari Carmen Reyes, Marc Sanz, Zoi Sucarrats, Joan Uribe y Mònica Vidal, y lo coordinaron los autores del presente artículo. El detalle de la información etnográfica obtenida sobre las hogueras de Sant Joan en Barcelona ya ha sido publicado (Contijoch y Fabré Nadal 2016), no así su consideración analítica, solo apuntada en esa obra. 
una treintena de casos se trató, pero, de entrevistas semiestructuradas y registradas, en las que los informantes se explayaban en detalles sobre cómo se procedía para llevar a cabo todo el protocolo que iba de la recogida de muebles viejos por el vecindario, hasta que se apagaban los últimos rescoldos de la hoguera que se había levantado con ellos.

Todas las personas a las que se recurrió para que narraran en qué consistió para ellos la noche de Sant Joan cuando fueron sus protagonistas relatan de manera parecida el proceso de preparación y encendido de la pira. Primero, se organizaba la pandilla que asumiría todo el procedimiento. La conformaban chiquillos, mayoritariamente varones que, días antes, iban casa por casa, tienda por tienda, taller por taller, almacén por almacén, pidiendo cualquier cosa que pudiera quemarse. Todo valía. Muebles para desechar que las familias conservaban hasta la visita de la chiquillería; cajas de madera que los tenderos les tenían reservadas, palés cedidos por cualquier taller... Una estampa frecuente era la de vecinos o empleados de tiendas y bares que iban a la busca de los mozalbetes para que les retiraran lo que fuere combustible que les sobrara, con lo que prestaban un servicio en un contexto en el que no existían las prestaciones públicas de recogida de trastos. La estampa de bandadas de niños corriendo a cualquier llamada de este tipo, arrastrando como podían todo tipo de objeto en condiciones de prender o bajando enseres voluminosos por las escaleras de cualquier finca, era la habitual (véase Figura 1). Luego, era cosa de escoger un buen escondite que protegiera lo recolectado de la depredación de otras pandillas y de la requisa de las brigadas municipales y, luego, de asegurar la vigilancia del depósito a lo largo de varios días mediante un sistema de guardias permanentes. El momento culminante era el de, llegado el anochecer de la víspera, sacar el tesoro de su escondrijo y amontonarlo en cualquier descampado, plaza o cruce de calles para hacerlo arder. Muchas veces se colocaba un maniquí de trapo culminando el montón de madera. En aquel momento, en Barcelona se encendían casi al unísono decenas de hogueras separadas entre sí en ocasiones apenas por unos cien metros ${ }^{6}$.

6 Es imposible establecer el número de hogueras que se encendían en Barcelona en la verbena de Sant Joan. En relación con el periodo estudiado -años 50, 60 y 70 del siglo XX- tuvieron que ser bastantes más de un millar en total en toda la ciudad. En 1970, ya iniciada la fase de decadencia, los bomberos informaban de 823 y en 1972 de 622 (Lladó 1972).

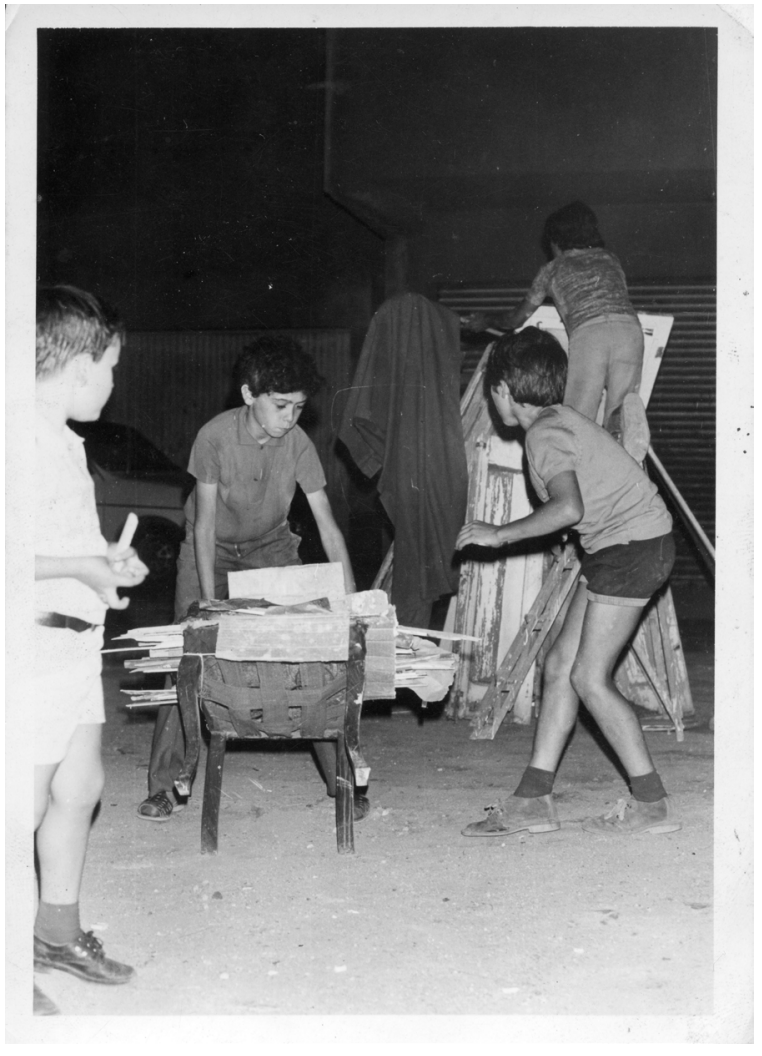

FiguRA 1.- Niños montando su hoguera de Sant Joan en alguna calle de Barcelona en junio de 1965. Autor desconocido/Arxiu Fotogràfic de Barcelona.

En concreto, se pudo establecer la situación y la fórmula previa de preparación de un total de 255 hogueras en 22 barrios de la ciudad, que reconocían la distribución territorial de la estructura social por clases. ${ }^{7}$ También los barrios escogidos representaban, como veremos, distintos tipos de morfología urbana, determinante para establecer la ubicación precisa de las fogatas: trazados reticulares como el del ensanche barcelonés, núcleos de calles estrechas e intrincadas como el casco viejo de Barcelona o el de poblaciones anexionadas, o polígonos de viviendas levantados en los años 50 y 60 . También se distribuyó la atención investigadora entre barrios de mayoría catalanoparlante y otros a los que fueron

7 Los barrios en los que se desarrolló la investigación fueron Sarrià, los tres Eixamples, Sant Ramon, les Corts, Gòtic, Gràcia, Camp d'en Grassot, Fort Pienc, Sant Antoni, Poblenou, Horta, Montbau, Sagrada Família, Guinardó, Baix Guinardó, Sagrera, la Verneda, Turó de la Peira, Vilapicina y Bon Pastor. 
a establecerse los flujos migratorios procedentes de otras regiones españolas, sobre todo del sur. La investigación no encontró evidencias de una diferente manera de preparar y encender las hogueras en unos barrios $u$ otros en función de ninguna de esas variables de clase, origen de la población, antigüedad del barrio o estructura urbana. Además de la labor de campo, una parte fundamental de la investigación consistió en un trabajo hemerográfico, bibliográfico y archivístico intensivo, que permitió recoger informaciones inéditas sobre la historia de las hogueras de la noche de Sant Joan en Barcelona, incluyendo las relativas a los continuados intentos de prohibirlas y sus justificaciones.

Partiendo de los datos obtenidos en esta investigación, el presente texto procura analizar los factores que pudieron determinar la casi desaparición de un determinado aspecto que fue central para una fiesta popular ${ }^{8}$, al menos en tanto que realmente popular, es decir, funcionando al margen o incluso en buena medida en contra de las instituciones oficiales y sus normativas a propósito de los usos festivos de la calle. Como se verá, más allá de otras causas, aparecerá como plausible que la extinción de esta costumbre no puede ser explicada sin tener en cuenta la disolución del sistema que la hacía posible y necesaria, puesto que era expresión de formas de apropiación colectiva del espacio urbano indesligables de la sociabilidad de barrio y, en concreto, del papel que en ella jugaban las colles ${ }^{9}$ de niños que encontraban en el espacio y el tiempo que se abrían entre la casa y el colegio un marco para una experiencia de autonomía y creatividad ${ }^{10}$.

8 Las expresiones "fiesta" o "cultura popular" que empleamos se identifican con el concepto de "popular" que usó Antonio Gramsci (2011 [1925-1935]) para referirse a formas expresivas propias de clases o sectores sociales subalternos, esto es instalados bajo o fuera de las esferas de poder.

9 Colla es un término que en Cataluña se usa de forma generalizada, también por la población castellanoparlante, para designar a cualquier grupo más bien pequeño de afinidad electiva y, en relación con preadolescentes y jóvenes, a la pandilla.

10 Conviene señalar que prácticamente todos los testimonios apuntaron que tanto la preparación y el encendido de las hogueras como buena parte de este universo del juego callejero del que formaban parte eran cuestiones en las que ellos tenían una mayor presencia. En efecto, estas diferencias en la mayor visibilidad de los niños en las calles y el mayor control familiar al que las niñas eran antes sometidas ponen sobre la mesa el modo en

\section{EL OCASO DE UNA FIESTA POPULAR}

Es complicado establecer con precisión cuando se empezaron a encender fuegos la noche de Sant Joan en el interior de las murallas de Barcelona, antes de su derribo en 1854. Las alusiones a la costumbre son abundantes a lo largo de los siglos XVIII y XIX, sobre todo relativas a los intentos gubernamentales de erradicarlas. Lo que sí que encontramos en las descripciones procuradas por los folkloristas románticos es el retrato del protagonismo de la canalla a la hora de recolectar muebles inservibles y atesorarlos hasta el momento de montar con ellos las piras y prenderles fuego en plazas, calles y descampados. Esa imagen aparece en el siglo XIX (Amades, 1983 [1953], V: 3334 ; véase Figura 2) y es la que conocerá de manera masiva cada noche de Sant Joan de todo el siglo XX, salvo en los años de guerra civil y hasta la década de los 80 . En ese tiempo, ningún programa de fiestas incluye las hogueras y las informaciones de la prensa solo aluden a ellas de paso, como si fuera una nota pintoresca más que da color a la celebración, una especie de trasfondo a propósito del que no valiera mucho la pena detenerse, salvo cuando puede atribuírsele alguna desgracia.

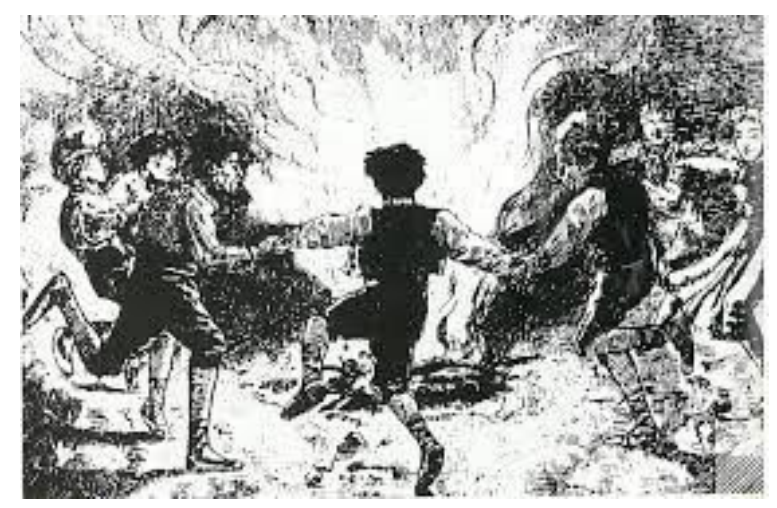

FIgURA 2.- Niños haciendo corro en torno a una hoguera. Grabado del siglo XIX recogido por Joan Amades en su Costumari Català (1983 [1953])

que los roles de género empezaban a interiorizarse y hacerse evidentes desde bien pequeños. Si bien esta cuestión queda en un segundo plano en el presente artículo, sí ha sido abordada en mayor profundidad en otras formalizaciones de los resultados de esta investigación (Fabré Nadal 2018). 
Como ya se hecho notar, en Barcelona de seguro que, en la década de los 50 y 60, tuvieron que encenderse no menos de un millar de hogueras, casi en su totalidad sin autorización municipal y al margen de cualquier control que no fuera la de los grupos de niños que las montaban en sus respectivos entornos cotidianos. Como contraste, en 2019, se quemaron la víspera de Sant Joan tan solo 16 hogueras. Esta ha sido la línea desde los años 90: 16 en 1993, 14 los años 2000 y 2001, 20 en 2006, 17 en 2007. A diferencia de las descritas por las personas entrevistadas, estas contaban con los preceptivos permisos de Ayuntamiento y Bomberos, así como su correspondiente seguro de responsabilidad civil, se instalaron sobre una base de arena proporcionada por una brigada municipal y se prendieron fuego bajo la supervisión de la Guardia Urbana. Cada una recibió solemnemente la Flama del Canigó, marca de la institucionalización política del rito ${ }^{11}$. Esta había sido recogida horas antes en la plaza Sant Jaume en un acto, presidido por autoridades municipales, por los equips de foc, conformados por asociaciones de vecinos, entidades culturales o esplais ${ }^{12}$, bajo la coordinación de la entidad Ómnium Cultural. Ya de madrugada, brigadas de limpieza municipal llegaban para borrar todo rastro de que en medio de cualquier plaza o cruce se había encendido un fuego. Y al día siguiente, los medios informarían del número de salidas llevadas a cabo por los servicios de emergencias y el cuerpo de

11 La Flama del Canigó es una llama permanentemente encendida en un farol conservado en el castillo de Perpiñán que, poco antes del 23 de junio, se distribuye a lo largo de las regiones catalanohablantes para encender las hogueras de Sant Joan, como símbolo de afirmación pancatalanista. A pesar de que su instauración data de 1956 y su llegada a Barcelona de finales de la década de 1960, en la investigación de campo ninguno de los informantes mencionó la intervención de la Flama en su respectiva hoguera y ni había siguiera oído hablar de ella en su momento.

12 Volveremos a su papel más adelante, pero adelantemos que los esplais son clubes de tiempo libre dedicados a convertir en educativo el ocio de los niños y jóvenes, muy extendidos en Cataluña desde mediados de los años 60 del siglo pasado. Nacen muy vinculados al movimiento scout y orientados por las nuevas tendencias educativas, entre ellas las relativas a la llamada «educación informal». En 2018, existían en Cataluña 113 esplais, a los que acudieron 17.129 niños y niñas, que participan durante las tardes y fines de semana en actividades lúdico-educativas dirigidas por 1.512 monitores. En Barcelona había activos ese mismo año 26 esplais, asociados a 422 entitades de soporte y 339 centros educativos <https://fundesplai. org/ca/inici-ca/7-fundacio-catalana-de-lesplai/16-memoria-d-activitats>, consultado 7/9/2019. bomberos, esto últimos sobre todo para apagar las pocas hogueras no autorizadas que algunos ciudadanos faltos de civismo habían prendido.

Las hogueras de Sant Joan iniciaron una decadencia imparable a partir de finales de los años 60 en Barcelona y, luego, en el resto de Cataluña. Esta decadencia parece intensificarse en los años 80, de manera que, en 1983, por ejemplo, fueron 193 las contabilizadas oficialmente ${ }^{13}$. En la década de 1990 se inaugura la tónica vigente hasta ahora de siempre menos de 20 hogueras autorizadas y un número indeterminado de no controladas, que fueron menguando en cantidad hasta prácticamente haber desaparecido en la actualidad. En cualquier caso, las pocas hogueras que han sobrevivido, incluso la no autorizadas, son encendidas por adultos. En Barcelona, se ha perdido por completo la tradición de la recogida de madera por parte de grupos de niños y niñas, que se encargaban de almacenarla, custodiarla y encenderla al anochecer de cada 23 de junio.

Parte del trabajo empírico en nuestra investigación sobre la memoria de las hogueras de Sant Joan en Barcelona consistió en preguntar a los informantes a qué atribuían su desaparición, al menos tal y como las habían conocido y practicado. Una de las causas más subrayadas fue la de los cambios generales en la morfología de la capital catalana, culminación de un proceso de urbanización que se consolida hacia la segunda mitad de la década de 1970. Desaparecen huecos urbanos, se edifica, las calles se asfaltan... No cabe duda de que estos factores han sido importantes, pero a la hora de otorgarles un valor determinante no hay que olvidar que las hogueras eran bien presentes en barrios que ya hacía décadas que habían sido plenamente urbanizados. De hecho, si hubiera un marco en el que la noche de Sant Joan brindaba un espectáculo más impresionante sería el de los barrios nacidos con la organización ortogonal del ensanche de Cerdà -los del Eixample, pero también Poblenou, Sagrada Família, Fort Pienc o Sant Antoni- consolidados desde hacia un siglo (véase Figura 3). Por otro lado, otra buena parte de la ciudad está configurada por barrios con estructuras premodernas, ya sean los de la propia Barcelona anterior a 1854 -Raval, Gòtic, Barceloneta, la Ribera, Poble Sec-o los que fueron municipios ane-

13 <http://hemeroteca.lavanguardia.com/edition.html?b$d=14 \& b m=06 \& b y=1984 \& x=45 \& y=13>$, consultado el 9/9/201. 
xados a la ciudad a finales del XIX y principios de XX: Gràcia, Horta, Sants, Sarrià, Sant Andreu, Sant Gervasi (véase Figura 4). En todos estos barrios, que no han sido afectados por las dinámicas de crecimiento urbano, se levantaron un día decenas de hogueras de las que solo queda el recuerdo.

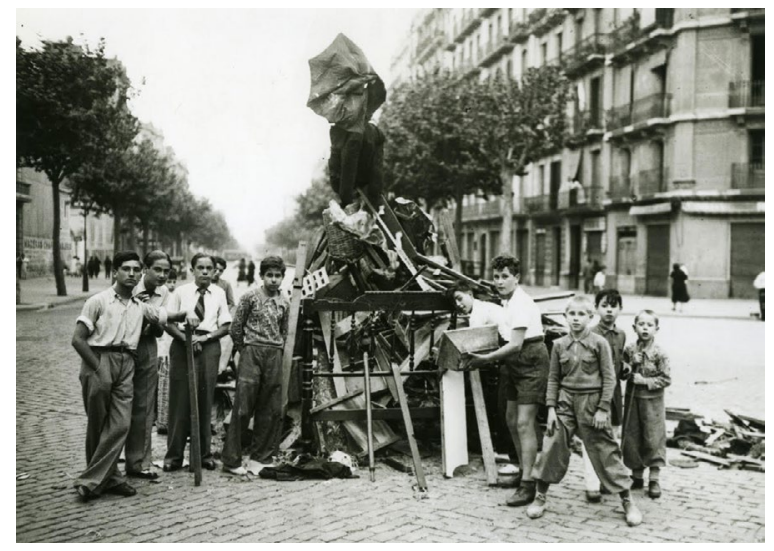

FIGURA 3.- Pira a punto de ser encendida en la calle Mallorca, en el Eixample barcelonés, en junio de 1935. Autor desconocido/Arxiu Fotogràfic de Barcelona

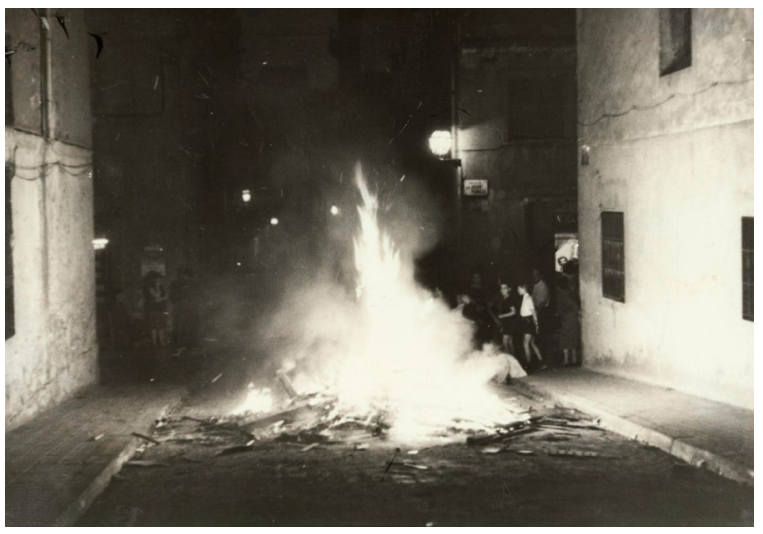

FIgURA 4.- Hoguera en el barrio de Sants en junio de 1964. Autor: Jaume Peris i Xancó/Arxiu Fotogràfic de Barcelona

En cuanto al proceso de automovilización, se apunta también como uno de los factores clave, por razones tanto técnicas como de seguridad, pero cabe insistir en que la localización revelada de las hogueras en los años 50 y 60 corresponde en muchos casos a vías céntricas -las de la amplia retícula abierta del ensanche barcelonés, por ejemplo- que en aquel momento ya registraban una densa presencia de circulación rodada. Y, cabe repetir, los barrios del casco antiguo de la capital o de las poblaciones incorporadas, constituían y continúan constituyendo zonas poco invadidas por el tráfico de vehículos debido a su enmarañada trama. Allí se levantaron hogueras; hoy, no. Y es igualmente cierto que no han hecho sino aumentar en toda la ciudad los espacios peatonales, sin que ello haya implicado un freno de la agonía de los fuegos de Sant Joan y menos su renacimiento.

De cualquier modo, la exposición a la calle como factor de riesgo nunca fue un obstáculo para la sociabilidad infantil en ella. Las familias sabían que dejar a sus hijos "salir a jugar» implicaba el riesgo cierto de recibirlos de vuelta señalados con todo tipo de heridas y hematomas, consecuencia de lo que eran verdaderas prácticas de riesgo, que iban de la apropiación aventurera de espacios potencialmente peligrosos -casas o fábricas abandonadas, descampados...- a refriegas a pedradas con pandillas rivales. Las propias operaciones que acompañaban todo el proceso de preparación de las hogueras ya eran imprudentes, puesto que implicaban acarrear y manipular objetos muchas veces pesados y con los que era fácil lastimarse con clavos o astillas. En cuanto a la actividad de la canalla la misma noche de la verbena -montaje y encendido de la hoguera, uso masivo de pirotecnia...--, difícilmente se podría encontrar mayor literalidad a la expresión «jugar con fuego».

También aparecía aducido como causa del fin de los fuegos sanjuaneros populares la instauración, en los años 90, de un servicio municipal de retirada de enseres y trastos viejos, que contribuyó a la pérdida de la costumbre por parte de los hogares de conservar sus deshechos mobiliarios hasta la visita de los niños y niñas para llevárselos. Pero en su última fase como celebración infantil y hasta la actualidad, en manos exclusivas ahora ya de adultos autorizados, el material combustible que arde está constituido por palés cedidos y por lo depositado en contenedores en la calle.

No cabe olvidar del papel negativo que para el mantenimiento de las hogueras urbanas tuvieron nuevas conductas de ocio familiar que irrumpen a mediados de los años 60, como las asociadas a las segundas residencias que se generalizan en esa época. En efecto, a partir de entonces muchas familias abandonan la ciudad la tarde del 23 de junio con el fin de pasar la verbena en sus pueblos de fin de se- 
mana o veraneo, en muchos casos con la finalidad de participar en ellos de las formas locales de la fiesta, incluyendo las correspondientes hogueras. Pero estas también han acabado desapareciendo en su mayoría, como si los llegados de la gran ciudad hubieran traído consigo el fin de la tradición.

En otra línea, hay testigos que informan de accidentes provocados por las llamas o de sanciones recibidas desde la autoridad, que habrían disuadido su continuidad en años posteriores. Actuaciones preventivas actuales, tales como acordonar un entorno para la hoguera, alejarla de cualquier cableado, despejar de vehículos la zona circundante, asegurar una distancia mínima de cualquier edificio, tal como se hace en las hogueras autorizadas de hoy en día, eran inconcebibles en aquellas descritas por las personas entrevistadas, todas encendidas sin permiso ni medidas de seguridad equiparables. De todos modos, si la siniestralidad hubiera sido una causa determinante, tal vez haría tiempo que la utilización masiva de pirotecnia las noches de verbena habría desaparecido. De hecho, el consumo de productos con pólvora no ha hecho sino aumentar $y$, al mismo tiempo, también ha crecido el de percances derivados de su uso ${ }^{14}$.

Otras referencias remiten a la persecución de que habría sido víctimas la costumbre por parte de las autoridades municipales de las últimas décadas. En la última etapa de los Ayuntamientos franquistas y desde la reinstauración de las instituciones democráticas, las normativas denominadas "cívicas» se habrían ensañado en borrar del mapa no sólo los fuegos de Sant Joan, sino toda manifestación festivs no patrocinada o cuanto menos fiscalizable desde el gobierno municipal. Pero esa preocupación por prohibir una expresión festiva como esta era vieja. Joan Amades (1983 [1953], IV: 33) menciona bandos municipales que prohibían el encendido de hogueras por Sant Joan ya en 1780. A partir de esa fecha no hay sino noticias constantes de prohibiciones y amenazas de sanción para un tipo de práctica festiva que acabó considerándose incontrolable (Cazenueve 2016), hasta tal punto era del todo imposible evitar que al anochecer de la víspera de Sant Joan apare-

14 Las informaciones previas a la noche de Sant Joan son, hoy, en realidad instrucciones de seguridad y las posteriores tienden a parecerse a partes de guerra. Por ejemplo, la noticia de la noche anterior en la televisión catalana el mediodía del 25 de junio de 2006: <https://www.youtube.com/watch?$\mathrm{v}=0 \_4 Z \mathrm{ZG} \times 06 \mathrm{Srk}>$. ciesen montones de enseres viejos que, escondidos antes y ahora arrastrados por la mainada, acabarían prendidos a lo largo y ancho de la ciudad.

Es cierto que bajo el mandato de José María de Porcioles -el alcalde franquista que en tantos sentidos preparó el camino para lo que luego sería el "modelo Barcelona"- arreció la ofensiva contra los fuegos sanjuaneros, lo que hizo que se pasara de tres intervenciones de los bomberos para apagarlos en 1964 a 43 en 1965, en una tónica que se mantendría hasta finales de los 70. Pero ya hemos hecho notar que a principios de esa década se encendían todavía cientos de hogueras en la ciudad. De hecho, casi todos los testimonios recogidos incorporan a su relato las estratagemas para proteger sus escondrijos de madera de las brigadas municipales que recorrían los barrios para requisarla. Incluso se refieren episodios de resistencia ante la llegada de los bomberos a pedradas o con cohetes. Eso quiere decir que la aplicación de las normativas tuvo un efecto importante, pero relativo, puesto que no impidió una reacción de indiferencia o resistencia en tanto y cuanto alguien estuviera a cargo de preparar las hogueras y prenderles fuego. En pocos años, ya no hicieron falta salidas de los bomberos para apagarlas, posiblemente porque acabaran acatándose los bandos y las normas, o acaso simplemente porque nadie desafió la prohibición de encenderlas.

Según datos brindados por el cuerpo de bomberos y ya aludidos, entre 1969 y 1983 desaparecen 630 hogueras de Sant Joan en Barcelona. Es la década de 1980 la que conoce la agonía definitiva de la costumbre de prender hogueras la noche del solsticio de verano, coincidiendo con las políticas de puesta a punto de Barcelona para ser colocada en el mercado de ciudades, más todavía a raíz de su proclamación como sede de los Juegos Olímpicos de 1992. Sin embargo, conviene poner en duda hasta qué punto este fenómeno fue consecuencia exclusiva o incluso principal de la presión de los primeros Ayuntamientos socialistas, en nombre de la estetización de la ciudad, contra cualquier expresión festiva no oficial. Es verdad que la ofensiva contra las hogueras incontroladas por parte de los gobiernos municipales posteriores a la recuperación de la democracia resultó fulminante (véase Figura 5), pero se ensañó contra una tradición moribunda desde muchos años antes y la obsesión municipal por acabar con ella no hizo más que agu- 
dizar y rematar una dinámica que hubiera sido imparable de todos modos.

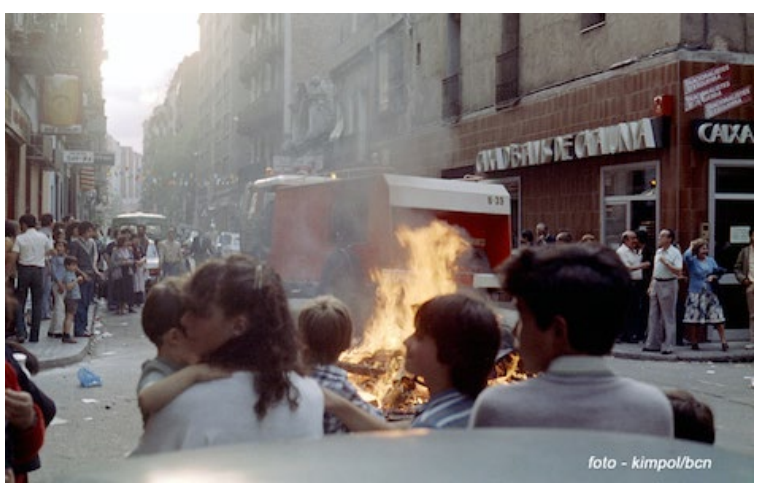

FIGURA 5.- Intervención de los bomberos para apagar una hoguera en el barrio de Poble Sec, en junio de 1980. Autor desconocido/Arxiu Fotogràfic de Barcelona.

En lo que coinciden casi todos los testimonios de la investigación, al ser interrogados sobre cómo y cuándo desapareció la que había sido "su» hoguera, fue a la hora de remitir a causas que no concretan, porque ninguno recordaba siquiera la verbena en que, por primera vez, dejó de formar parte central de la fiesta y menos el por qué. Se habla de que «quizás» fue un nuevo asfaltado, algún siniestro, una multa..., pero no se era capaz de señalar con precisión en qué momento y por qué motivo dejó de haber una hoguera por Sant Joan donde siempre y «desde siempre» la había habido. En realidad, la mayoría de los comentarios a propósito de la ausencia de la hoguera de su calle solo daban cuenta de que, un día, nadie pasó a recoger muebles viejos por su casa, ni vio a partidas de niños acarreándolos de un sitio a otro, ni pudo asistir a como alguien los amontonaban en el lugar habitual -el de la permanente quemadura en el suelo- y les hacía arder.

\section{HOGUERAS E INFANCIA DE CALLE ${ }^{15}$}

Los recuerdos de todos los informantes masculinos y buena parte de los femeninos coincidieron a la hora

15 No olvidamos en ningún momento que «infancia» es una categoría émic propia de las sociedades urbano-industriales ya naturalizada a escala mundial. Nada que añadir a lo puesto de relieve por Ariès (1973) o Chombart de Lauwe (1979) acerca de la invención de la infancia como una etapa vital segregada, que aparece con las nuevas jerarquizaciones por rango de edad que acompañan el proceso de modernización. de evocar lo que fueron un día como «chavas de barrio»: todas las tardes "bajaban a la calle», desde que salían del colegio hasta que los llamaban para cenar, como también buena parte de los festivos y las vacaciones escolares. Se organizaban en pandillas de vecindad y que les comprometían en todo tipo de encuentros recurrentes, aventuras compartidas, escondites, competencia con otras pandillas. Eran niños y en menor medida niñas que "bajaban a la calle», es decir que tenían en los alrededores de su casa el marco territorial en que se desarrollaba una parte importante de su vida cotidiana, que incluía una red de ubicaciones significativas, algunas de ellas secretas. Lugares aparentemente insignificantes eran escenario de aventuras imaginarias y actividades que podían llegar a convertirse en una suerte de pruebas iniciáticas. Por supuesto que la calle era también espacio natural de una amplia gama de juegos. La mainada transformaba el espacio urbano en un universo de rincones e intersticios convertidos en escondrijos $y$ refugios, en los que se desarrollaba una intensa vida social hecha de intercambios, complicidades y rivalidades. Estas últimas se trasladaban a las hogueras, donde la dinámica de rivalidad se expresaba en el tamaño y el éxito que lograba cada colla con la suya, así como en robos furtivos de material de la contraria en los días previos.

No parece que fuera hace mucho que ese alboroto infantil llenaba multitud de rincones de Barcelona. Pero eso ocurría también en todas las grandes ciudades de las sociedades urbano-industriales. en que se daba lo que William F. Whyte (2015 [1943]) Ilamara, titulando un libro memorable Las sociedades de las esquinas, dedicado a las pandillas juveniles en el North End de Boston de principios de los años 40. Jane Jacobs (2011 [1961]) consagrará un capítulo de su obra más conocida a la manera como los niños norteamericanos estaban siendo víctimas de una de las que define como supersticiones del urbanismo, que asume que hay que arrancarlos de la corrupción de la calle para colocarlos, escribe con ironía, en «espacios abiertos para correr y hierba para elevar sus espíritus. ¡Lugares limpios y felices llenos de la risa cantarina de los pequeños agradecidos por un ambiente sano!» (103). Allí, continua más adelante, podrán «aplicarse a juegos reconocidos (¿reconocidos por quien?)» (114), en sitios dispuestos oficialmente para hacer, encajonados en una especie de reserva, lo que ya se ocupaban de hacer correteando libres por las aceras. 
Luego, Colin Ward (1978), un historiador social de filiación libertaria, dedicará una obra fundamental a ese mismo fenómeno en las ciudades inglesas a lo largo del siglo XX, en ella reconocía en la vida pública independiente de niños y niñas una madurez capaz de desarrollar una sociabilidad estructurada y funcional, con un papel activo y determinante en la cotidianidad de sus entornos urbanos, una vida que producía una cultura paralela, casi contestataria, que tomaba las calles como espacios de resistencia al modelo de infancia impuesto institucionalmente. Un universo de iniciativas consistentes en una exploración sistemática de una geografía hecha de rincones y escondrijos, que reimaginaban de manera singular el espacio urbano y encontraban en él el escenario para un cúmulo de nuevas experiencias (Skelton y Valentine 1998; Holloway y Valentine 2000; Ortiz Guitart 2007). Esta vida de pandilla ocupaba solo una faceta de la cotidianidad de sus miembros, y cobraba vida en los intersticios del tiempo ocupado por otras instituciones reconocidas como la escuela, la familia, la iglesia e incluso el trabajo, resquicios a la vez topográficos y sociales de y en el espacio urbano que, como una suerte de inframundo, aparecía en las fisuras del orden social de los adultos.

Esas pandas de chavales que desplegaban su noche de Sant Joan en Barcelona hacían de esta la expresión «en abierto» de una vida social mucho más amplia y compleja, constante, pero medio oculta, que era manifestación de un fenómeno global del que eran escenario muchas otras ciudades del mundo industrializado. Lo protagonizaban corporaciones infantiles basadas en la asociación habitual y en un sistema de obligaciones mutuas que hilvanaban sus miembros a través de toda una red de vínculos de lealtad, solidaridad y grado siempre revocables, que se constituían en un auténtico aparato pedagógico paralelo y autonormativizado. A través de este, los más jóvenes aprendían acaso las cosas que más determinantes resultarían para perfilar su forma de pensar y de ser en lecciones que se impartían mutuamente camaradas de aventuras callejeras. Todo ello se disolvería al final de la adolescencia con la progresiva incorporación al mundo adulto de sus miembros.

Se configuraba en ese proscenio -los exteriores urbanos- una cultura propia, aquella que ha abordado esta rama de los estudios culturales Ilamada children's street culture (Ward y Fyson 1973; Hart 1979; Valentine, 2004; Thompson 2013), pero que ya era detectada en los trabajos folklorísticos sobre cultura infantil
(Bronner 1988) ${ }^{16}$. En este caso, entendiendo «cultura» a la manera clásica de los fundadores de la antropología, como cuando Joan Amades (2006 [1936]) abordaba el mundo de los grupos de edad infantiles como ejemplos de culturas "primitivas», con sus estructuras y formas de autoridad y solidaridad propias y, por supuesto, sus creencias y sus ritos, destacando entre ellos los relativos a un culto solar singular, del que todo lo relacionado con las hogueras de Sant Joan podía ser tomado como expresión (74-76).

Para los informantes de nuestra investigación, la evocación de las hogueras de Sant Joan implicaba no solo reconocer en las apropiaciones infantiles del espacio urbano que ellos mismos protagonizaron un valor meramente sentimental, decorado biográfico de tantas primeras experiencias. Más allá, la calle tenía un papel fundamental en su proceso de socialización, ya que debía ser escenario de vivencias que, incluso bajo el aspecto de juego, forjarían conocimientos y habilidades sociales que, como se ha remarcado, no proveían ni el aparato escolar ni la formación hogareña. Subrayemos que de esta experiencia infantil del exterior inmediato de la casa nace en buena medida lo que entendemos que es un barrio, como construcción para un tipo de vínculo social basado en la proximidad y en la rutina de los encuentros en un contexto territorial delimitado, pero ante todo como aula natural que permitió el paso gradual de este espacio que llamamos privado a aquel otro de la interacción despersonalizada entre desconocidos y con desconocidos que caracteriza la plena vida urbana.

Es a esta vivencia infantil del espacio contiguo al domicilio que se le encomiendan socialmente tareas fundamentales en la formación de las personas, confiadas al grupo de edad -la colla- y bajo la discreta vigilancia de los vecinos. Aquí se establecía el mol-

16 No confundir esta problemática de los niños en la calle en las ciudades del mundo industrializado con la de los niños de la calle de las del llamado "Tercer Mundo" y ahora también de las nuestras: gamines colombianos, meninos da rua brasileños, talibés senegaleses, nuestros menas. El tratamiento tanto de uno asunto como otro coinciden en la consideración de los menores como individuos desamparados e hipervulnerables si carecen de adultos cerca que les protejan, incapaces de desarrollar formas propias y eficientes de adaptación a su entorno, sea para jugar o para sobrevivir, así como, por supuesto, fuentes de inquietud social como consecuencia de la libertad con que hacen propio el espacio urbano. 
de o configuración básica de cualquier modalidad de apropiación psicológica y afectiva del espacio, de cualquier espacio, ya que ejercía una función simbólica mediadora que hacía posible superar el abismo brusco que se habría producido, si no hubiera existido, entre lo que es completamente público y lo que es completamente privado (Mayol 1999).

En efecto, la noche de Sant Joan era la protuberancia festiva de la vida social de una quitxalla que recibía en ese momento especial la oportunidad de visibilizarse como institución social no reconocida, pero clave para una vida de barrio que, en realidad, era vida a secas. Esa noche era el momento elegido para una especie de insurrección festiva de los niños ${ }^{17}$, la oportunidad de escenificar una suerte de revancha contra los adultos, en un ejemplo de aquellos ritos de rebelión o de inversión simbólica por medio de los cuales sectores subordinados de cualquier sociedad asumen el control provisional del espacio y del tiempo, a la vez que hacen patentes contenciosos y rencores con aquellos que durante el tiempo «normal» los dominan, e insinúan de paso su poder oculto.

\section{LA EDUCACIÓN EN EL OCIO Y EL ACUARTELAMIENTO DE LA INFANCIA}

Lo que se está sosteniendo es que fueron clave para la paulatina desaparición de los fuegos populares de Sant Joan procesos como los de urbanización, automovilización, nuevos empleos del tiempo de ocio familiar y, sobre todo, la aplicación de edictos y normativas relativas al buen uso del espacio público. Pero que también lo fue, desde aquel mismo momento, la extinción gradual de lo que había sido una intensa sociabilidad infantil de calle, que anunciaba la desactivación tanto de la infancia como esfera autónoma autogestionada por los propios niños, como de la calle misma como lugar de coincidencia y como instrumento al servicio de una vida colectiva basada en la proximidad.

Esta custodia cada vez más intensa y continuada de la actividad infantil en general, y en la calle en particular, -es decir, la pérdida de control parcial de los niños sobre sus vidas- sería síntoma de cambios culturales

17 La propia tradición catalana recoge este tipo de fiestas de venganza infantil de origen medieval y extensión europea -reis d'Innocents, bisbes de burles, bisbes dels nois. (Amades 1983 [1953], I: 217-252), algunas vigentes hasta ahora, como la de los bisbetons en Montserrat. significativos. Por un lado, la asunción, general ya, de una concepción de la niñez como una etapa de total indefensión y dependencia. Al mismo tiempo, se produce la universalización de discursos del miedo que muestran la calle como una fuente de riesgos tanto físicos como, sobre todo, morales. Estos relatos entienden que la exposición no supervisada de los menores a la vida en el exterior implica ponerlos a merced de todo tipo de accidentes, del acecho de desconocidos y de las malas compañías, así como de hábitos inconvenientes, vicios e incluso a la marginalidad y la delincuencia (Chombart de Lauwe et al. 1976). De igual concepción de la calle como ámbito malformativo se deriva una problematización del tiempo que los todavía no adolescentes pasan fuera de los ámbitos familiar y escolar, que se traduce, por parte de los padres, en restricciones temporales, espaciales y de movilidad que llevan al enclaustramiento de los niños en actividades supervisadas en fragmentos de espacio público perimetrados -una especie de reservas- o en locales cerrados.

El tiempo infantil se concibe, cada vez más, como un tiempo que debe emplearse de forma productiva en lugar de "malgastarse» en juegos no controlados en la calle, donde, se repite, «no se aprende nada bueno». Veremos enseguida que el tiempo fuera de la supervisión de la familia y la escuela es convertido en tiempo también de aprendizaje formal, combinando preocupaciones de carácter didáctico con otras que pretenden convertir el momento de juego en un espacio educativo, seguro y libre de todo riesgo. El juego infantil independiente se percibe además como una molestia para el buen empleo del espacio público y de ahí los carteles de "prohibido jugar a la pelota» que se multiplican por doquier en tantas ciudades.

Aparecen entonces las ludotecas, los centros consagrados a impartir todo tipo de aprendizajes complementarios, todo aquello que garantice que los más jóvenes tengan ocupado el tiempo extraescolar. Al mismo tiempo, los espacios al aire libre de la ciudad se llenan de recintos rodeados de vallas, que adoptan forma de corral y en que los niños juegan al amparo de un entorno que se presupone hostil y peligroso. Llegado el fin de semana y el verano, un enorme número de pequeños son enviados a campamentos o casas de colonias. A un nivel superior, las más altas instancias internacionales suscitan redes de «ciudades educadatoras» y "ciudades amigas de la infancia», cuya vocación es convertir un día a los niños en ciudadanos informados de virtudes cívicas. 
Una tendencia educativa irrumpió en su momento para darle forma doctrinal a esa nueva preocupación por salvar a los niños y jóvenes de la calle. Se trata de la "pedagogía del ocio», que asumió la tarea de dirigir a los menores hacia ocupaciones y actividades fructíferas y beneficiosas durante el tiempo desocupado -es decir sin obligaciones ${ }^{18}-$ del que disponen. Tiene su primera expresión en las colonias escolares higienistas de finales del siglo XIX y su versión militarista en el movimiento scout que funda Baden Powell en 1907. Con esos precedentes la ciencia pedagógica, adoptando y adaptando ahora perspectivas progresistas y sociales, diseña metodologías y programas de actuación para la fiscalización de lo que había sido el tiempo libre de los niños, iniciativas que tienen expresiones tanto laicas como religiosas y que pronto se incorporan a las políticas educativas oficiales.

Completando el currículum escolar y la formación familiar, los niños pasan así a quedar a disposición de la "animación educativa», una didáctica no formal al servicio del «crecimiento personal» de seres gestionados como inmaduros, incompletos y por hacer. Se fundamenta sobre todo en un repertorio de discursos ideológicos reformistas que, por encima de su diversidad, coinciden en su pretensión de inculcar de cerca los principios abstractos y universales de la «civilidad» y la "ciudadanía», léase de la constitución de sujetos políticos adecuados para los requerimientos de la organización estatal de la sociedad, es decir en condiciones de establecer entendimiento adecuado con las estructuras públicas y conocer y manejar los códigos que le permiten a estas obtener obediencia voluntaria de sus administrados.

\section{MONITOREO DE LA INFANCIA Y NEUTRALIZACIÓN DE LA CANALLA EN CATALUÑA. LOS ESPLAIS}

El proceso de paulatina desaparición de las hogueras de Sant Joan en Barcelona, a partir de mediados de los años 60 del siglo pasado, coincide con la simultánea y también gradual retirada de la canalla de la vida de calle, indesligable de el auge que conocen esas alternativas pedagógicas destinadas a hacer

18 Toda la pedagogía del tiempo libre se despliega dispuesta a llenar ese tiempo que la definición clásica de ocio define como "sin obligaciones» con todo tipo de obligaciones programadas. Al respecto de las pretensiones de la educación en el ocio, véase Puig Rovira y Trilla (2000). productivo el tiempo libre de niños y jóvenes. Es en ese momento que, de la mano tanto de las corrientes progresistas de la Iglesia como del asociacionismo laico, se expande en Cataluña esa pedagogía del tiempo libre a la que acabamos de referirnos (Serra i Garcia 1968; Balcells y Samper 1993; Samper 1993). Se concreta en la proliferación de los ya aludidos centros de esplai y de agrupacions escoltes, esto es de grupos scouts. Este tipo de activismo educativo, pensado para una adecuada guía del ocio infantil y juvenil, aparecía como alternativa al casi monopolio que las organizaciones juveniles franquistas -la Organización Juvenil Española y el Frente de Juventudes- habían ejercido para el adoctrinamiento de los más jóvenes y se le reconocen unas implicaciones políticas notables en la fase de decadencia de la dictadura y la salida a flote de la oposición democrática (Sureda 1998).

Las corrientes de renovación pedagógica higienista y filantrópica tienen precedentes en Cataluña desde finales del siglo XIX y hay movimiento boy scout desde 1912 , pero son aquellos 60 cuando conocen un auge que los convertiría enseguida en centrales para una reorganización del tiempo infantil y juvenil. Ello puede asociarse a la aparición de corrientes de renovación pedagógica de las que el momento referencial sería la aparición de la Escola de Mestres Rosa Sensat, en octubre de 1965. A partir de ese momento, una parte importante de la población infantil es colocada por las familias bajo la tutela del movimiento escolta y el asociacionismo educativo para el tiempo libre, que asumen la tarea de ofrecer actividades extraescolares tales como campamentos de verano, excursiones, talleres, juegos educativos y prácticas deportivas, que se desarrollan o fuera de la ciudad o en espacios cerrados como caus, esplais y casals ${ }^{19}$, y solo eventualmente en exteriores urbanos. En todos los casos, siempre bajo la dirección de jóvenes mayores de edad, llamados monitores, cuya función es, precisamente, la de monitorizar -esto es escrutar y controlar- la actividad de los menores a su cargo (Franch y Martinell 1984).

Al margen del ya referido papel político que tuvo el movimiento de los esplais en las postrimerías del franquismo, la incidencia fundamental y más pro-

19 Los caus -en catalán, madriguera o guarida- es el nombre de los locales de reunión de las agrupaciones escoltas en Cataluña, esplai remite tanto al club de ocio infantil como al lugar en que su ubica y casal se refiere a la sede de una asociación en general. 
funda de las asociaciones para el buen provecho del tiempo libre, como en otros países, fue la de ofrecer alternativas a lo que había sido la actividad no controlada en la calle y encauzar la actividad de niños y niñas para hacer de ellos escolares fuera de la escuela. De hecho, no se oculta por parte de sus cronistas que la corriente surgió en un contexto urbano -Barcelona y su conurbación- y no solo para atender los jóvenes y niños que ya participaban de los campamentos de verano -raíz del asociacionismo para la educación en el ocio-, sino sobre todo para «integrar» el alud de menores hijos de familias procedentes de la inmigración que se habían asentado en la capital catalana y en los grandes núcleos obreros de su periferia. Así, la creación de esplais en Cataluña en los años 60 fue «un fenómeno propio de los núcleos urbanos que forman el cinturón metropolitano [...] receptores que fueron de enormes contingentes de pobladores suministrados por las grandes olas migratorias de origen rural». En este contexto, "los centros de esplai consiguieron reunir a parte importante de jóvenes y residentes, hasta convertirse en un elemento de vertebración e integración, tan abundantes como sólidos» (Adroher, Jiménez y Vallory 2005: 81).

La función que se atribuía este tipo de alineamiento pedagógico fue estimular la implicación personal, la participación y la adopción de responsabilidades, las mismas tareas que ya desarrollaba la pandilla de calle, solo que ahora auspiciadas por una instancia que actuaba como delegada autorizada para extender a lo que había sido tiempo libre la tarea formativa encomendada a las familias y la educación formal. En realidad, la verdadera educación informal era la que autoimpartía la propia colla, que ahora quedaba postergada por algo así como una educación informal formalizada, es decir sometida de manera indirecta a las lógicas de integración en el sistema político-institucional. Ello a la manera de un verdadero para-aparato ideológico del Estado... «informal», es decir aparentemente al margen del Estado ${ }^{20}$. De ahí que un manual de formación de monitores pueda teorizar acerca de que el esplai hace propia la lógica del pequeño grupo -que ya era el de la pandilla- como marco organizati-

20 Aunque fuera, como en el caso del inicio del movimiento de los esplais en Cataluña, como preparación para un sistema político en ciernes, en un contexto, el del tardofranquismo, en que se percibía como inevitable el tránsito a la democràcia formal una vez desaparecido el dictador. vo ideal de niños y jóvenes «en situaciones de ocio» o en «situaciones informales de tiempo libre» (Franch 1985: 32) y de que el objetivo del club de ocio era «la integración de los pequeños grupos y de las relaciones que se establecen entre ellos, en una red de relaciones institucionales» (Franch y Martinell 1984: 23). En el caso del movimiento escultista la absorción del modelo organizativo y formativo de la pandilla adoptó un referente militar: la patrulla.

En cualquier caso, la implantación en Cataluña de la pedagogía del ocio, asumida por los centros de esplai y el movimiento scout, supuso la retirada masiva de niños de la calle, una labor que continuaba y completaba la que fuera indispensable en su día para la implantación de la enseñanza obligatoria. En efecto, fue la misma alarma ante los peligros de una exposición excesiva de los niños a los peligros de la calle lo que estuvo en España el centro de los discursos acerca de la escuela como cúpula protectora de los males de la gran ciudad (Sirera Miralles 2016). Aquello se tradujo en el toque de queda para los menores de edad en horario escolar, que el control sobre el tiempo libre ampliaba indirectamente al resto de la jornada y de la semana. Hoy, la presencia de preadolescentes y adolescentes solos en la calle se ha convertido en una anomalía que ha hecho del «menor no acompañado» una de las figuras de la exclusión social, cuando no de la delincuencia ${ }^{21}$.

\section{A MODO DE CONCLUSIÓN. LA RECUPERACIÓN DEL ESPACIO PERDIDO}

En ciencias sociales explicar consiste en poner de manifiesto cómo unos hechos $-y$ sus propiedadesestán en relación con otros hechos $-\mathrm{y}$ con sus propiedades- y cómo esa relación entre hechos y propiedades puede ser reconocida como constituyendo un cierto sistema. En este caso hemos propuesto una puesta en relación entre la extinción de las hogueras de Sant Joan, la disolución de lo que fue la cultura infantil de calle en las ciudades y la generalización de instancias de educación en el tiempo libre que supri-

21 Uno de los pocos reductos que quedan de actividad infantil en la calle sería el que puede contemplarse a la hora de salida de los colegios y en su entorno inmediato y en el camino a casa de los escolares, algo que los pedagogos del tiempo libre también codician fiscalizar (Trilla 2004). Un trabajo interesante sobre ello es el de Laia Llonch (2019). 
mieron la presencia de los niños y niñas del ahí afue$r a$, todo ello con el substrato ideológico de la mala reputación atribuida a la calle como lugar de riesgo y depravación.

Es decir, el declive y muerte de toda forma de cultura popular no puede aprehenderse sin atender la disolución del sistema que la hacía posible y necesaria. Este sería, sin duda, el caso de las hogueras de Sant Joan, que eran expresión de formas de apropiación colectiva del espacio urbano inseparables de la sociabilidad de barrio y, en concreto, del papel que ejercían las asociaciones informales de adolescentes y preadolescentes que encontraban en el espacio que se abría entre la casa y la escuela el marco para una experiencia de independencia y responsabilidad. A su vez, privando a los niños de la calle, se ha privado la calle de la dosis supletoria de enredo y creatividad que ellos siempre estaban en condiciones de añadir. Ahora bien, tal enajenación no ha quedado impune.

Lluís Mallart, uno de nuestros africanistas más destacados y con mayor proyección internacional, dedica las primeras páginas de Sóc fill dels evuzok (2021 [1972]) a una evocación de su infancia jugando en las calles del barrio de Sarrià poco después de acabada la guerra civil. Refiere cómo «la calle era un gran espacio en el que se cumplía una parte importante de nuestro proceso de socialización». En efecto, en ella «las emociones, la sexualidad, la solidaridad, los antagonismos, las distinciones sociales se aprendían en ese territorio que de día era nuestro". Ya de noche, «cuando los mayores salían con las sillas para conversar y tomar el fresco, nosotros lo aprovechábamos para ir más allá, correr, perseguirnos [...], como para significar que queríamos conquistar nuevos espacios alejándonos de la mirada de aquella sociedad adulta que parecía querernos contener». Al final, «con los años los pequeños perdimos el control de aquel espacio que había sido nuestro [...] La chiquillería fue recluida en casa» ${ }^{22}$.

Pero, en el relato de infancia con el que abre su libro sobre los evuzok, Lluís Mallart advierte de cómo

22 En una comunicación personal posterior, en agosto de 2019, Mallart nos explicaba como también tenían «su» hoguera en los años 40. La montaban en el cruce de la calle Calatrava con la calle Dalmases, casi en el límite de Sarrià con el barrio de la Bonanova. Días antes iba con su pandilla por las casas a recoger trastos y muebles viejos que guardaban hasta la vigilia de Sant Joan. Recuerda aquella noche como el gran acontecimiento para el y para la muchachada del barrio. esa expulsión de los niños de la calle tuvo sus consecuencias en forma de una suerte de venganza de quienes, adolescentes o ya mayores de edad, recuperaban aquel espacio que les había sido enajenado: «El ruido de las motocicletas rompiendo la tranquilidad de los adultos es un signo. Las pintadas en las paredes señalando la conquista de calles y plazas es otro». Añade: "Uniendo estos dos signos podríamos decir que el ruido de las motocicletas es el 'grito' de una reivindicación y las pintadas de los taggers es la "firma"». Confirmando esa impresión, bien podríamos decir que esa revancha contra el mundo de los adultos -representado tanto por los padres como por maestros, autoridades y, por supuesto, «animadores»- se ha venido expresando en todo tipo de formas inapropiadas de apropiación del espacio público. La proliferación de jóvenes skaters deslizándose por las aceras parecería una respuesta a la prohibición de patinar por la calle que les afectó cuando eran quitxaIla. Los botellones a veces masivos en lugares públicos serían otro ejemplo de su recuperación insolente por parte de unos jóvenes que tuvieron que esperar a serlo para conocer la potede los exteriores urbanos para el encuentro autónomo y autogestionado.

En Barcelona, cada año hay un eco de esa búsqueda del espacio perdido la noche de Sant Joan. En efecto, la agonía de las hogueras coincide de manera gradual, a lo largo de los años noventa, con el apogeo de una práctica festiva nueva. Es a partir de la apertura de nuevas playas en Barcelona -parte de las reformas preolímpicas- que decenas de miles jóvenes -60.000 en $2019^{23}$ - deciden pasar la noche de verbena en ellas, distribuyéndose en corrillos en cuyo centro a veces arde una pequeña hoguera ${ }^{24}$. A la mañana siguiente, la prensa presenta esa ocupación masiva de las playas como un problema de salud pública e incivismo -el estado deplorable de la arena, con toneladas de residuos acumulados- y como una cuestión de orden público a la hora de desalojar a los concurrentes llegado el alba. Se consuma así el desquite de quienes no pudieron ejercer su derecho a gozar por cuenta propia del aire libre de las ciudades,

23 <https://www.elperiodico.com/es/sociedad/20190621/ verbena-sant-joan-playas-7516264>. Consultado el 9/9/19.

24 La primera información sobre la ocupación de las playas esa noche en la prensa correspondió a la celebración de $2002<$ http://hemeroteca.lavanguardia.com/edition.ht$\mathrm{ml}$ ?bd $=24 \& b m=06 \& b y=2002 \& x=39 \& y=35>$. Consultado el $9 / 9 / 19$. 
al tiempo que queda demostrado que, muchas veces, a la muerte de una tradición la acompaña la aparición de otra, que viene a cubrir esa misma necesidad que cada sociedad y cada segmento de sociedad experimentan de celebrarse cíclicamente a sí mismos.

\section{BIBLIOGRAFÍA CITADA}

Adroher, Raul, Elena Jiménez y Eduard Vallory (eds.) 2005. Escoltisme laic $i$ transformació social. L'experiència $d^{\prime}$ Escoltes Catalans. Vic: Eumo Editorial.

Amades, Joan. 1983 [1953]. Costumari català. El curs de l'any. Barcelona: Salvat.

Amades, Joan. 2006 [1936]. Cultura infantil. Tarragona: L'Àguila de la cultura popular.

Ariès, Philippe. 1973 [1960]. L'enfant et la vie familiale sous l'Ancient Régime. París: Seuil.

Balcells, Albert y Genís Samper. 1993. L'escoltisme català (1911-1978). Barcelona: Ed. Barcanova.

Bronner, Simon, J. 1988. American Children's Folklore. Little Rock: August House.

Cazeneuve, Xavier. 2016. "Història de la festa de Sant Joan a Barcelona», en Roger Canals et al., La Nit de Sant Joan a Barcelona: 18-47. Barcelona: Angle/Ajuntament de Barcelona.

Chombart de Lauwe, Marie-José. et. al. 1976. Enfant en jeu. Les practiques des enfants durant leur temps libre en fonction des types d'environment et des idéologies. París: Éditions du CNRS.

Chombart de Lauwe, Marie-José. 1979. Un monde autre: l'enfance. De ses représentations à son mythe. París: Payot.

Contijoch, Marta y Helena Fabré Nadal. (eds.) 2016. La ciutat de les fogueres. Els focs de Sant Joan i la cultura popular infantil de carrer a Barcelona. Barcelona: Pol-len Edicions.

Fabré Nadal, Helena. 2018. "Memorias de mujeres de la Vila de Gràcia. Historias de infancia y de barrio entre el inicio de la guerra civil y el franquismo tardío", en María Gabriela Navas y Muna Makhloufa (coords.). Apropiaciones de la ciudad. Género y producción urbana: 187-219. Barcelona: Pol.len Edicions.

Franch, Joaquim y Alfons Martinell. 1984. L'animació de grups d'esplai i de vacances. Fer de monitor. Barcelona: Ed. Laia.

Gramsci, Antonio. 2011 [1925-1i35] ¿Qué es la cultura popular? València: Universitat de València. Servei de Publicacions.

Hart, Roger. 1979. Children's Experience of Place. Nueva York: Irving.

Holloway, Sarah. L. y Gill Valentine. (dirs.). 2000. Children's Geography. Playing, Living, Learning. Londres: Routledge.
Jacobs, Jane. 2011 [1961]. Muerte y vida de las grandes ciudades. Madrid: Capitán Swing.

Laforet, Carmen. 2012 [1944]. Nada. Barcelona: Destino.

Lladó, Josep Maria. 1972. «La noche de Sant Joan, fiesta del fuego y del amor». Tele/Exprés, 21 de junio de 1972: 21.

Lloch, Laia. 2019. Canalla i espai urbà a Castellà del Vallès. Una etnografia amb nens i nenes d'11-12 anys de l'escola Joan Blanquer. Barcelona: Universitat de Barcelona, Departament d'Antropologia Social, Trabajo Final de Máster. Inédito.

Mallart, Lluís. 2021 [1992]. Soc fill dels evuzok. La vida d'un antropòleg al Camerun. Barcelona: Debutxaca.

Mayol, Pierre. 1999. "Habitar», en Michel de Certeau, Luce Giard y Pierre Mayol. La invención de lo cotidiano. 2. Habitar, cocinar: 5-12. México DF: Universidad Iberoamericana.

Monnet, Nadja y Mouloud Boukal (coords.). 2018. Explorer la ville - Le rapport aux espaces publics des enfants et des adolescents, Enfances, familles, génerations, 30, número monográfico.

Ortiz Guitart, Anna. 2007. "Geografías de la infancia: descubriendo 'nuevas formas' de ver el mundo». Documents d'Anàlisi Geogràfic, 49: 197-216.

Puig Rovira, Josep Maria y Jaume Trilla. 2000. La pedagogía del ocio, Barcelona: Laertes.

Samper, Genís. 1993. 50 anys d'escoltisme català. Barcelona: Secretaria General de la Joventut.

Sirera Miralles, Carles. 2016. "Los peligros de la gran ciudad: percepción de la relación entre pubertad y espacio urbano a mediados del siglo XIX», en Joan Carles Colomer Rubio y Josep Sorribes (coords.), València, 1808-2015: la història continua... Vol. 1.: 549-562 Valencia: Balandra Edicions.

Skelton, Tracey y Gill Valentine (eds.) 1998. Cool Places: Geographies of Youth Cultures. Londres: Routledge.

Sureda, Bernat. 1998. «Participación cívica y cambio político en educación (1970-1995)». Revista Española de Pedagogía, 56 (210): 371-396.

Thompson, Mathew. 2013. Lost Freedom: the Landscape of the Child and the British Post-War Settlement. Oxford: Oxford University Press.

Tonucci, Francesco. 2018. Manual de guerrilla urbana. Para niñas y niños que quieren conocer y defender sus derechos. Barcelona: Graó.

Trilla, Jaume. 2004. «Los alrededores de la escuela». Revista española de pedagogía, 62 (228): 305-326.

Valentine, Gill. 2004. Public Space and the Culture of Childhood. Gran Bretaña: Ashgate Publishing Limited.

Ward, Colin. 1978. The Child in the City. Londres: The Architectural Press Ltd.

Ward, Colin y Anthony Fyson. 1973. Streetwork: the Exploding School. Londres: Routledge. 